Abstract S43 Table 1 Mean within subject\% change, coefficient of variation and biological variability in pulmonary function between timepoints

\begin{tabular}{llll}
\hline & Mean\% change $(95 \% \mathrm{Cl})$ & Mean CV $(\mathbf{9 5 \%} \mathrm{Cl})$ & $\begin{array}{l}\text { Biological Variability } \\
(97.5 \% \mathrm{Cl})\end{array}$ \\
\hline $\mathrm{FEV}_{1}$ & $4 \%(-2-10.1)$ & $10.1 \%(6.7-13.5)$ & $0.15 \mathrm{~L}$ \\
$\mathrm{FEF}_{25-75}$ & $6.9 \%(-5.2-19)$ & $20.3 \%(14.1-26.5)$ & $0.21 \mathrm{~L} / \mathrm{s}$ \\
FVC & $3.3 \%(-0.8-7.1)$ & $6.9 \%(4.6-9.2)$ & $0.15 \mathrm{~L}$ \\
$\mathrm{R5}$ & $-1.8 \%(-12.7-10.9)$ & $16.1 \%(11.6-20.6)$ & $0.07 \mathrm{kPa} / \mathrm{L} / \mathrm{s}$ \\
R20 & $4.8 \%(-2.4-11.9)$ & $12.5 \%(9.2-15.8)$ & $0.03 \mathrm{kPa} / \mathrm{L} / \mathrm{s}$ \\
AX & $-12.2 \%(-39.6-15.8)$ & $39.2 \%(28.9-49.6)$ & $0.39 \mathrm{kPa} / \mathrm{L}$ \\
$\mathrm{F}_{\text {res }}$ & $-0.6 \%(-9.1-7.9)$ & $14 \%(9.4-18.5)$ & $1.5 \mathrm{~Hz}$ \\
\hline
\end{tabular}

$\mathrm{AX}=$ area under the reactance curve; $\mathrm{F}_{\text {res }}=$ resonance frequency; $\mathrm{R} 5=$ resistance at $5 \mathrm{~Hz}$; $\mathrm{R} 20=$ resistance at $20 \mathrm{~Hz}$; Within subject biological variability was calculated as a onesided $97.5 \% \mathrm{Cl}$. Other $95 \% \mathrm{Cl}$ were two-sided.

meaningful response in severe asthma patients. Hence for AX a change $\geq 0.39 \mathrm{kPa} / \mathrm{L}$ is required to represent a clinically meaningful response.

Conclusion In conclusion, we report on medium term repeatability for IOS and spirometry and propose values for within subject biological variability in patients with poorly controlled severe asthma.

\section{S44 BRONCHODILATOR RESPONSE FOR AIRWAY OSCILLOMETRY IN SEVERE EOSINOPHILIC ASTHMA}

R Chan, CRW Kuo, BJ Lipworth. Scottish Centre for Respiratory Research, Dundee, UK

\subsection{6/thorax-2021-BTSabstracts.50}

Introduction Bronchodilator response (BDR) is conventionally defined as a $200 \mathrm{ml}$ or $12 \%$ improvement in $\mathrm{FEV}_{1}$. In mild to moderate asthma, forced oscillation technique (FOT) BDR is closely related to asthma control. ${ }^{1}$ FOT BDR in patients with severe eosinophilic asthma (SEA) is however unknown.

Aim To determine relative BDR for spirometry and airway oscillometry (AOS, Thorasys Tremoflo) in SEA.

Methods Preliminary baseline data from a prospective study (EudraCT No. 2019-003763-22) are presented on SEA patients in response to $400 \mu \mathrm{g}$ salbutamol.

Results Mean values were age 52, $\mathrm{FEV}_{1} 74 \%, \mathrm{FEF}_{25-75} 41 \%$, R5 184\%, ACQ 2.9, Eosinophils 576 cells/ $\mu$ l, FeNO 54ppb and BDP equivalent ICS dose $1809 \mu \mathrm{g}$.

Mean absolute changes were: $\mathrm{FEV}_{1} 0.202 \mathrm{~L} \quad(\mathrm{p}<0.001)$; $\mathrm{FEF}_{25-75} 0.308 \mathrm{~L} / \mathrm{s}(\mathrm{p}<0.001)$; resistance at $5 \mathrm{~Hz} \mathrm{R} 50.12 \mathrm{kPa} /$

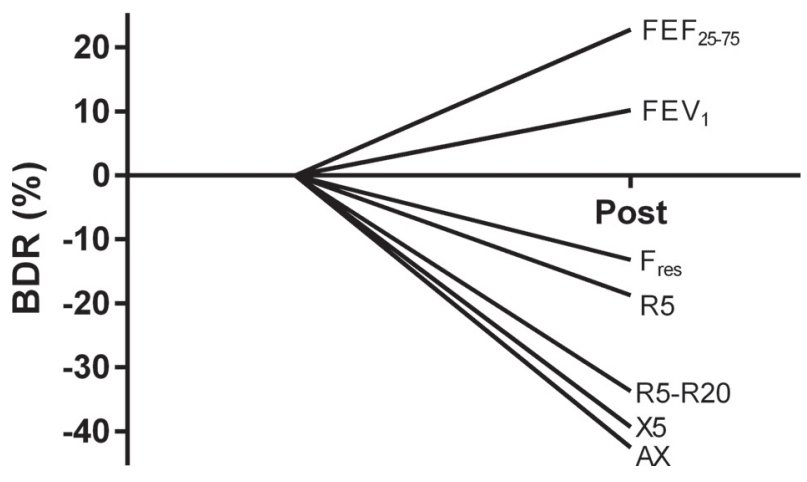

Abstract S44 Figure 1
$\mathrm{L} / \mathrm{s} \quad(\mathrm{p}=0.001)$; peripheral airway resistance between 5 and $20 \mathrm{~Hz} \mathrm{R} 5-\mathrm{R} 200.08 \mathrm{kPa} / \mathrm{L} / \mathrm{s} \quad(\mathrm{p}=0.005)$; reactance at $5 \mathrm{~Hz} \times 5$ $0.19 \mathrm{kPa} / \mathrm{L} / \mathrm{s} \quad(\mathrm{p}=0.011)$; reactance area $\mathrm{AX} 2.07 \mathrm{kPa} / \mathrm{L}$ $(p=0.016)$ and resonant frequency $\mathrm{F}_{\text {res }} 3.17 \mathrm{~Hz} \quad(\mathrm{p}=0.034)$. The relative $\%$ BDR improvements were greatest for R5-R20, $\mathrm{X} 5$ and AX reflecting small airways (figure 1). The standardised response mean (SRM) expresses the signal to noise ratio as mean change divided by $\mathrm{SD}$ which were: $\mathrm{FEV}_{1}$ 2.02; $\mathrm{FEF}_{25-75} 1.6$; R5 1.36; R5-R20 1.06; AX 0.87 and $\mathrm{F}_{\text {res }} 0.93$ ( $\mathrm{RRM} \geq 0.80$ are considered highly sensitive).

Conclusion The relative\% BDR was greater for AOS than spirometry, although conversely the SRMs were better for spirometry than AOS.

\section{REFERENCE}

1. Kuo CR, Chan R, Lipworth B. Impulse oscillometry bronchodilator response and asthma control. J Allergy Clin Immunol Pract. 2020;8(10):3610-2.

\section{S45 A PUFF OF SUGAR AND A PINCH OF (SPEECH \& LANGUAGE THERAPY) SALT: IS THE MANNITOL CHALLENGE TEST A USEFUL INGREDIENT IN THE ASSESSMENT OF INDUCIBLE LARYNGEAL OBSTRUCTION?}

${ }^{1} \mathrm{C}$ Slinger, ${ }^{1} \mathrm{~A}$ Vyas, ${ }^{1} \mathrm{H}$ Lever, ${ }^{2} \mathrm{R}$ Slinger, ${ }^{3} \mathrm{~J}$ Silva, ${ }^{1} \mathrm{C}$ Prior. ${ }^{1}$ Lancashire Teaching Hospitals, Preston, UK; ${ }^{2}$ Lancaster University, Lancaster, UK; ${ }^{3}$ University Hospitals of Morecambe Bay, Lancaster, UK

\subsection{6/thorax-2021-BTSabstracts.51}

Introduction In our Tertiary Airways service, we assess for contributors of complex breathlessness, such as asthma and inducible laryngeal obstruction (ILO). Tey et al (2017) studied inhaled mannitol for investigation of laryngeal and bronchial hyper-responsiveness, and concluded inhaled mannitol can be used to induce ILO. Previous studies found abnormalities of the inspiratory flow volume loop (FVL) can indicate need for further investigation of ILO.

Objectives To assess if mannitol challenge testing (MCT) is a useful adjunct in the assessment of ILO, and to measure interrater reliability between professionals.

Methods We reviewed 41 consecutive patient records undergoing both MCT and laryngoscopy (undertaken separately) over 15 months. An "upshift" of inspiratory FVL between baseline and maximal dose of inhaled mannitol was taken as indicative of provoking ILO. Ratings of the inspiratory FVL were conducted independently by two speech and language therapists (SLT 1 and 2), a consultant physician and a Respiratory physiologist.

Results Of 41 patients, 25 (61\%) had confirmed diagnosis of ILO. Agreement between laryngoscopic diagnosis of ILO and rating of the inspiratory FVL following MCT varied between raters. FVL ratings by SLT 1 agreed with laryngoscopy results 31 times (80\%), compared to $27(68 \%)$ agreements by SLT 2, $22(59 \%)$ by the physician and $20(54 \%)$ by the physiologist.

Kappa statistics showed moderate agreement between laryngoscopy and FVL for SLT $1(\mathrm{k}=.55)$, but weak agreement for SLT $2(k=.34)$ and no agreement for the physician or physiologist.

A binary logistic regression assessed the relationship between laryngoscopy outcome and FVL ratings by SLT 1 . The model was significant $\left(\chi^{2}=12.44(1, \mathrm{~N}=41) \mathrm{p}=.002\right)$ indicating that FVL predicted laryngoscopy outcome, and explained between $24 \%$ and $33 \%$ of the variance. 